\title{
Student attitudes towards cooperative construction education experiences
}

Theo C Haupt, Research Coordinator (Faculty of Engineering, Peninsula Technikon, South Africa)

\section{ABSTRACT}

This paper reports on the findings of a study that examined the attitudes of students at a historically disadvantaged institution (HDI) compared with those at a previously advantaged institution (PAI) in South Africa. PAls in South Africa have been almost exclusively white in the past while HDIs have been predominantly black - both with respect to their academic staffing and student population. It is argued that higher education institutions have given students in general too little that will be of real value beyond a credential that will help them get their first jobs. The opinions of first year students were surveyed before, and third and final year students after, their practical periods of employment in construction. The study concludes that all the cooperative partners in cooperative education can do much more to improve this approach to construction education.

Keywords-cooperative education, experiential training, practical experience, higher education, employment

\section{INTRODUCTION}

In South Africa two primary forms of institutions, namely universities and technikons, dominate the higher education sector, each with historically distinctive characters. Generally speaking, South African universities are quite similar to universities in other parts of the world. Arguably they provide substantive underpinning scientific knowledge that enables and equips graduates to engage with wide knowledge-intensive activities such as research and development. On the other hand technikons, the subject of this particular study, are similar to the polytechnics of the early 1990s in the United Kingdom. They are somewhat different from traditional universities with respect to their pedagogic emphasis and target student population. Historically they have trained para-professionals and technologists in the application of existing technologies to the workplace. Technikons have generally been described as offering cooperative or work-based education.

However, in the face of recent government-driven restructuring of the higher education landscape each type of institution has been compelled to revisit and redefine its traditional and historical role-universities with respect to their primarily academic focus and technikons with respect to their primarily career-oriented and technological focus. Consequently, the 'gap' between technikons and universities has been steadily narrowing with technikons becoming more like the technical universities and institutes of technology of the United States and elsewhere.
Apart from the historical pedagogic differences between universities and technikons in South Africa, the higher education sector has not gone unaffected by the racial inequalities that underpinned the policies of the previous apartheid dispensation. In terms of these policies education institutions were directly affected by disparate and unequal government funding as well as racial segregation both with respect to academic staffing and students. Recent government policies have been designed to redress these past inequalities as well.

Cooperative education as the pedagogic approach followed by technikons embodies the notion that both education and training are equally essential. Education, on the one hand, has been described as all the ways in which people train and develop to fulfil their potential as a result of acquiring skills, attitudes, and values which reflect the social, cultural, and physical environments in which they live (Guillaud and Garnier, 2001). Training, on the other hand, is the systematic development of attitudes; knowledge and skill patterns required by an individual to perform adequately a given task or job. Cooperative education, therefore, aims to prepare people for the world of work within their socio-civic environments.

Higher education has as one of its objectives the preparation of persons to address emerging societal problems. Institutions serving this education sector have a major role to play in providing the technological and business capability to underpin modern industrial and services development (Frain, 1992). Higher education teaches and trains people to fulfil specialised social functions, enter the learned professions, or pursue vocations in administration, trade, industry, science and technology and the arts (White Paper, 1997). While maintaining the commitment to high academic standards, higher education institutions also need to be committed to responding to the needs of industry both in course content and research. However, there is a need to balance the relationship between theory as taught in the classroom and practice in the field or industry (Ross and Elechi, 2002). Several authors have highlighted that apart from course content relevant to job-related situations, there should be an appropriate teaching approach that bridges the perceived gap between formal academic instruction and on the job training (Kim, Williams and Dattilo, 2002; Sanyal, 1991; Ellington, Gordon and Fowlie, 1998; Schaafsma, 1996). This gap between what is taught in classrooms and what is 
needed in the workplace is well illustrated in Table 1 adapted from Cook and Cook (1998).

\begin{tabular}{|l|l|}
\hline & Requirements \\
\hline Traditional education & Facts \\
& Individual effort \\
Passing a test \\
Achieving a grade \\
Individual courses \\
Receive information \\
Teaching separate from learning \\
\hline Workplace & Problem solving \\
& Team skills \\
& Learning how to learn \\
Continuous improvement \\
Interdisciplinary knowledge \\
Interact and process information \\
Technology
\end{tabular}

Table 1. Traditional education vs Workplace

(Source: Cook and Cook, 1998)

The separation between practical and academic work creates a division in the mind of students rather than relating the theory to the application that reinforces the basic concepts taught in the classroom. There are few studies, if any, that evaluate the relationship between construction theory as taught in the classroom and construction practice in the field from students' perspectives. In particular, there is very little published research on the effectiveness of the latter aspect. This paper reports on the findings of a study that examined the attitudes of students at technikons in South Africa regarding their experiences of transferring theory to the workplace. Further, the paper also reports on whether there was any difference between the attitudes of students who attended a previously advantaged institution (PAl) and those who attended a historically disadvantaged institution (HDI).

\section{COOPERATIVE EDUCATION}

Cooperative education is an educational model designed to achieve the objective of bridging the gap between the classroom and the workplace by incorporating productive work experiences into the curriculum as an integral and regular element of a higher education program. As such it involves three cooperative partners, namely the academic institution, the student, and the employer (Smith, 2000). It has been described as an instructional method that links classroom instruction and work for the purpose of enhancing the total educational program of students (Schaafsma, 1996). It is therefore evident that the cooperative education experience comprises of two components, namely an academic component and an experiential learning component. During the latter component students experience a range of learnings (Knowledge, skills and attributes) that are a direct outcome from linking the specific experience in the workplace with the course content provided in a higher education institution. The experiential learning or work-based learning component is also known as industrial placement or work placement and is described as a period of time when students are located in workplaces with the purpose of learning on the job which might either be paid or unpaid (Schaafsma, 1996). As such it provides the underpinning knowledge and attributes of competence needed for the job as a whole such as workplace culture, work norms and values. This particular approach provides opportunities for students to have direct hands-on experience as part of their course of study. In this way students are prepared for their future careers. They acquire valuable and specialised knowledge and skills by learning from experience and reflecting on that experience while becoming acquainted with the work processes (Hicks, 1996; Rainsbury et al, 1998).

This form of experiential learning may be expressed as the combination of three elements, namely programmed learning in structured settings, questioning learning gained via investigation and research, and own experience (Hicks, 1996).

Apart from cooperative education contributing to more effective learning (Schaafsma, 1996) it also has the potential to be mutually beneficial to both students and employers (Frain, 1992). Employers benefit from having a significant influence on course design and content by ensuring that industry-specific knowledge, awareness and values are integrated into the higher education process. Students benefit from working as they experience firsthand and come to understand the requirements of their chosen career. As they engage in the actual activities in the workplace they gain appreciation for the challenges of their particular job (Ross and Elechi, 2002). They are consequently better able to make informed decisions on their career choices. They also develop enhanced appreciation of concepts learned in the classroom after applying knowledge in a professional setting (Gordon, Hage and McBride, 2001). This working or in-service period is often the students' first opportunity to apply theoretical, classroom-based knowledge in a practical work situation. They gain a more realistic view of how the world of work operates. Work experience is often a strong determining factor in whether or not students find employment. Cooperative education provides the opportunity for students to enhance their prospects of employment once they graduate (Frain, 1992). They are given the opportunity to demonstrate their abilities to prospective employers. Through this approach, they already have work experience at the moment of academic graduation. Students are introduced to the work ethic, and gain insight into the interpersonal skills needed to survive in the working world (Schaafsma, 1996). They see the opportunities for career development and personal growth that are open to them in their field of study.

Traditionally the academic institution evaluates both the academic and experiential learning components using 
feedback from students through academic evaluation programs and feedback from employers through records of employment activities in, for example, logbooks. Several authors have argued for a more inclusive and participatory approach to evaluation that includes the academic institution, the employer and the student (Hicks, 1996; Rainsbury et al., 1998). The collaboration between the academic institution and employers emphasises the connection between academic preparation and job requirements. It is argued that such a cooperative approach offers greater opportunities to blend academic and practical skills.

\section{SOUTH AFRICAN COOPERATIVE EDUCATION CONTEXT}

The Constitution of the Republic of South Africa, 1996 (Act 108 of 1996), states in section 29 (1) that: 'Every one has the right:

- To a basic education, including adult basic education; and

- To further education which the state, through reasonable measures, must make progressively available and accessible'.

With respect to higher education in South Africa, the challenge facing the new democratically elected government is to redress past inequalities and to transform the existing higher education system to serve a new social order, to meet pressing needs, and to respond to new realities and opportunities (White Paper, 1997). Further, the higher education sector needs to provide education and training that develops the skills and innovations necessary for national development and successful participation in the global economy. It is the South African government's stated policy that cooperative education should bridge the minds of students at higher education institutions such as technikons and the industry in which they hoped to develop their future careers. To achieve this national objective, technikons and universities have to pursue strong relationships with, and input from, stakeholders and industry concerning their fields of study. These industry-sensitive programs need to be designed to help students in their transition from school to the workplace. Industry employer representatives suggest that education and training offered at higher education institutions such as technikons are inadequate for the needs of their industries. They argue that graduates lack the necessary theoretical skills, training and managerial understanding to ensure immediate meaningful employment, creating a mismatch between what employers appear to want and what higher education provides (Graham and McKenzie, 1995). This perceived mismatch contributes to unemployment and the lack of advancement opportunity. Construction graduates are ill prepared to contribute to the economic growth of the country, less able to adapt to new skills, and less able to respond to the speed of technological advance. Higher education institutions and technikons in particular are therefore faced with both challenges and opportunities to contribute to the achievement of national economic priorities through relevant cooperative education programs.

The current higher education system is distinguished to the extent that programs and qualifications are poorly articulated, inhibiting student mobility between institutions and leading to high levels of inefficiency. Programs generally, and between HDls and PAls, differ widely with respect to quality, standards of provision, outcomes and curriculum. Separate education and training tracks reflect rigid and outmoded distinction between academic education and vocational training. Consequently, technical and vocational education lack parity of esteem with traditional university based schooling. New entrants into the South African labour market generally lack appropriate knowledge and skills.

Employers argue that many programs offered at technikons, in particular, are irrelevant and outdated. Equipment is antiquated and tuition is poor overall quality. HDls lack meaningful linkages with industry and have largely been disconnected from the local economy. The converse is true of PAls who have optimised their links with industry to secure access of their graduates to the labour market and economy. Envisaged institutional redress of the inherited inequalities between HDIs and PAls while not necessarily intensifying, has not diminished. Consequently, a distorted labour market is perhaps the most visible legacy of apartheid-a system designed to empower a minority by the exclusion and subsequent marginalisation of the majority. These problems are exacerbated by low enrolments in engineering and technology-fields essential to the achievement of higher levels of technological innovation and productivity (White Paper, 1997). Additionally, there is the perception that construction students attending HDls are less prepared for the world of work than their counterparts at PAls. In practice this perception affects their access to suitable industry placements as employers preferentially employ graduates from PAls.

\section{RESEARCH}

In South Africa, technikons offer construction-related programs on the basis of cooperative education. The four year Bachelor of Technology program is made up of three academic years spent full time at the institution with the second year spent full-time working in industry. During this 'experiential year' students complete projects in 3 subjects, namely Construction Management 2, Construction Technology 2 and Quantity Surveying 2. Students are also required to keep a logbook of all their work activities on a monthly basis. The logbook sets out the required activities that students are expected to experience. In order to return to the institution to complete the remaining two years students have to obtain passing grades in each of these subjects as well as submit a duly completed logbook. 


\section{Sample selection}

Between September and October 2002 students were surveyed at two technikons where construction-related programs were offered, one being a historically disadvantaged institution (HDI) and the other a previously advantaged institution (PAI). A total of 107 first year students and 54 third and final year students participated in the survey. The questionnaires were administered at the respective institutions during sessions when the students were receiving instruction. Consequently, the response rate was $100 \%$. The responses to the questionnaires were analysed using the Statistical Program for the Social Services (SPSS).

\section{Survey instrument}

Two short questionnaires were developed, namely one for students in first year who would spend their next year in an industry placement and the other for returning students who had already completed their 'experiential year'. The first year questionnaire was designed to determine the attitude of students about the content of the first year subject offerings and their relevance to their experiential year. It also sought to establish what they expected from this year in industry. The other questionnaire was designed to obtain the opinions of students after the experiential year. The questionnaires comprised of both open and close-ended ('yes,' 'no' and 'not sure') questions. Several questions used a 5-point Likert scale to determine the degree of sentiment expressed in the preceding response. The strength of close-ended questions is that they foster uniformity in response due to the limitation of the number of possible responses. On the other hand, open-ended questions provide the possibility of rich contextual information being collected in a manner not possible with close-ended questions (Fellows and Liu, 1997).

\section{FINDINGS}

The responses to each of the questionnaires are reported for the entire sample and by institution. Descriptive statistical findings in the form of frequencies and measures of central tendency are reported for each of the variables. The author recognises and accepts the limitation common to most surveys of the self-declarations of the respondents with respect to knowledge, attitudes, beliefs and behaviours.

\section{First year students survey}

The sample comprised of 107 first year students, namely 60 $(56.1 \%)$ fro.n the PAl and $47(43.9 \%)$ from the $\mathrm{HDI}$. Of those who responded, there were $59(60.2 \%)$ students studying quantity surveying, and $39(39.8 \%)$ studying construction management -9 students failed to respond to this question.

\section{First year course content expectations}

There was generally a favourable attitude towards the first year course content. From Table 2, it is evident that 80 students $(75.5 \%)$ felt that the first year course content was what they expected it to be when they applied for it; 15 students (14.2\%) felt that it was not; and the remaining 11 students (10.4\%) were not sure.

A smaller proportion of students at the $\mathrm{HDI}(69.6 \%)$ than at the PAI $(80.0 \%)$ felt that the first year course content met their expectations. On the other hand, a larger proportion of students at the $\mathrm{HDI}(17.4 \%)$ than at the PAI (5.0\%) were unsure about whether the course met their expectations or not.

\begin{tabular}{|l|c|c|c|c|c|c|}
\hline & \multicolumn{2}{|c|}{ Sample } & \multicolumn{2}{c|}{ PAI } & \multicolumn{2}{c|}{ HDI } \\
\hline & Freq. & Valid \% & Freq. & Valid \% & Freq. & Valid \% \\
\hline Yes & 80 & 75.5 & 48 & 80.0 & 32 & 69.6 \\
\hline No & 15 & 14.2 & 9 & 15.0 & 6 & 13.0 \\
\hline Not sure & 11 & 10.4 & 3 & 5.0 & 8 & 17.4 \\
\hline Total & 106 & 100 & 60 & 100 & 46 & 100 \\
\hline
\end{tabular}

Table 2: Expectations of first year course content

Reasons given for why students felt that the course content was what they expected included

- Subjects were based on and related to industry;

- Knew and expected course to be intense, tough and relevant;

- Worked in and knew construction before and therefore knew what to expect;

- Researched program before starting studies; and

- Provided information as expected.

Reasons for why they thought the course content was not what they expected included

- Not all subjects were what I expected or relevant;

- Thought it would be simple and not so difficult;

- Expected more practicals; and

- I did not expect it to be so academic.

\section{Relevance and responsiveness} of first year courses to industry needs

Most students had a favourable attitude about both the relevance of the subjects offered for the course as well as their responsiveness to the needs of the construction industry. It is evident from the data in Table 3 that 96 students $(90.6 \%)$ believed that the subjects offered were relevant and responsive to the needs of the industry.

\begin{tabular}{|l|c|c|c|c|c|c|}
\hline & \multicolumn{2}{|c|}{ Sample } & \multicolumn{2}{c|}{ PAI } & \multicolumn{2}{c|}{ HDI } \\
\hline & Freq. & Valid \% & Freq. & Valid \% & Freq. & Valid \% \\
\hline Yes & 96 & 90.6 & 54 & 90.0 & 42 & 91.3 \\
\hline No & 5 & 4.7 & 3 & 5.0 & 2 & 4.3 \\
\hline Not sure & 5 & 4.7 & 3 & 5.0 & 2 & 4.3 \\
\hline Total & 106 & 100 & 60 & 100 & 46 & 100 \\
\hline
\end{tabular}

Table 3: Relevance and responsiveness of course 
The responses were similar for students at either of the institutions about the relevance and the responsiveness to the needs of the construction industry of the subjects offered at first year.

Reasons given for why students felt that the course content was relevant and responsive to the needs of construction included

- Subjects provide insight into the industry;

- Class work relates to the industry;

- Subjects are adequate at year 1 and basic and relevant to the industry; and

- Worked in industry before studying.

Reasons for why they thought the course content was not relevant and responsive included

- Some subjects were either irrelevant or needed more time and/or better teaching; and

- Some more subjects needed to be added to make it better.

\section{Satisfaction with subjects offered for the course}

The majority of students expressed satisfaction with the subjects that they had been offered during their first year. From Table 4 it is evident that 74 students $(69.2 \%)$ were satisfied with the subjects offered while 21 students (19.6\%) were not.

A smaller proportion of students at the $\mathrm{HDI}(66.0 \%)$ than at the PAI $(71.7 \%)$ felt satisfied with the subjects offered at first year. On the other hand, a larger proportion of students at the $\mathrm{HDI}(23.4 \%)$ than at the PAI (16.7\%) were dissatisfied with the subjects.

\begin{tabular}{|l|c|c|c|c|c|c|}
\hline & \multicolumn{2}{|c|}{ Sample } & \multicolumn{2}{c|}{ PAI } & \multicolumn{2}{c|}{ HDI } \\
\hline & Freq. & Valid \% & Freq. & Valid \% & Freq. & Valid \% \\
\hline Yes & 74 & 69.2 & 43 & 71.7 & 31 & 66.0 \\
\hline No & 21 & 19.6 & 10 & 16.7 & 11 & 23.4 \\
\hline Not sure & 12 & 11.2 & 7 & 11.7 & 5 & 10.6 \\
\hline Total & 107 & 100.0 & 60 & 100.0 & 47 & 100.0 \\
\hline
\end{tabular}

Table 4: Satisfaction with subjects offered during first year

Reasons given for why students were satisfied with the subjects offered during first year included

- Based on experience [of first year] subjects are OK and relevant;

- Challenging but fair;

- Lots of practical exposure provided;

- Increases understanding of the industry;

- Something I just needed to do; and

- Gives advantage for later profession.
Reasons for why students were not satisfied with the subjects offered during first year included

- Not all subjects are relevant; some were disorganised and others needed more [instruction] time; and

- Subjects are fine but lecturers are not.

Those students who were not sure about whether they were satisfied or not with the subjects offered indicated that they

- [Were] not sure of what to expect on site; and

- Cannot comment/ not sure.

Course as preparation for year 2

Most students felt that the first year course prepared them sufficiently for year 2 . The data in Table 5 indicate that 72 students $(68.6 \%)$ thought that the course prepared them adequately for their second year-the experiential/in-service year. On the other hand, 20 students $(19.0 \%)$ were not sure whether this was so or not.

\begin{tabular}{|l|c|c|c|c|c|c|}
\hline & \multicolumn{2}{|c|}{ Sample } & \multicolumn{2}{|c|}{ PAI } & \multicolumn{2}{c|}{ HDI } \\
\hline & Freq. & Valid \% & Freq. & Valid \% & Freq. & Valid \% \\
\hline Yes & 72 & 68.6 & 44 & 74.6 & 28 & 60.9 \\
\hline No & 13 & 12.4 & 3 & 5.1 & 10 & 21.7 \\
\hline Not sure & 20 & 19.0 & 12 & 20.3 & 8 & 17.4 \\
\hline Total & 105 & 100.0 & 59 & 100.0 & 46 & 100.0 \\
\hline
\end{tabular}

Table 5: Course as preparation for year 2

A smaller proportion of students at the $\mathrm{HDI}(60.6 \%)$ than at the PAI $(74.6 \%)$ felt that the first year course prepared them sufficiently for year 2 . On the other hand, a larger proportion of students at the $\mathrm{HDI}(21.7 \%)$ than at the PAI $(5.1 \%)$ felt that the first year course did not prepare them sufficiently for year 2 .

Reasons given for why students thought the first year course prepared them sufficiently for year 2 included:

- Theory prepares for practical;

- Provides [the] basics for industry experience [although] the industry is broad; and

- Provided you worked throughout the year.

Reasons for why students thought the first year course did not prepare them sufficiently for year 2 included

- Some subjects don't have assignments/practicals;

- Year 1 [was] too short;

- Need to work with real materials in workshop sessions; and

- Some lecturers do not know their subjects [well enough] to prepare us. 
Those students who were not sure whether the first year course prepared them sufficiently for year 2 or not indicated that they

- Don't know what to expect from in-service training; and

- Did not understand initially and might not be ready.

\section{Academic or practical nature of first year course}

Opinions were more divided with respect to whether students felt that the course was too academic and less practical. From Table 6 it is evident that 39 students (38.2\%) thought that the course was too academic while 51 students $(50.0 \%)$ did not think so. The remaining 12 students (11.8\%) were not sure.

\begin{tabular}{|l|c|c|c|c|c|c|}
\hline & \multicolumn{2}{|c|}{ Sample } & \multicolumn{2}{c|}{ PAI } & \multicolumn{2}{c|}{ HDI } \\
\hline & Freq. & Valid \% & Freq. & Valid \% & Freq. & Valid \% \\
\hline Yes & 39 & 38.2 & 24 & 41.4 & 15 & 34.1 \\
\hline No & 51 & 50.0 & 27 & 46.6 & 24 & 54.5 \\
\hline Not sure & 12 & 11.8 & 7 & 12.1 & 5 & 11.4 \\
\hline Total & 102 & 100.0 & 58 & 100.0 & 44 & 100.0 \\
\hline
\end{tabular}

Table 6: Academic or practical nature of course

A smaller proportion of students at the $\mathrm{HDI}(34.1 \%)$ than at the PAl $(41.4 \%)$ felt that the course was too academic and less practical. A larger proportion of students at the HDI $(54.5 \%)$ than at the PAI $(46.6 \%)$ felt that the course was not too academic.

Reasons given for why students thought the first year course was too academic and less practical included

- Practicality needs more emphasis;

- More practicals [and] site visits;

- I wanted a more practical course; and

- Course seems more practical.

Reasons for why students thought the first year course was not too academic and less practical included

- Balanced approach; and

- Academic side is very important.

\section{Senior students survey}

This sample comprised of 66 students, namely 24 (36.4\%) from the PAI and $42(63.6 \%)$ from the HDI. Of those who responded, there were $37(60 \%)$ students studying quantity surveying, and $26(40 \%)$ studying construction management -3 students failed to respond to this question. With respect to the year of study, 59 students $(89.4 \%)$ were in their third year and 7 students $(10.6 \%)$ were in their final (4th) year. All the students at the PAI who participated in the survey were third year students.

\section{Year 2 experiential training}

Almost all these students (58 students; $87.8 \%$ ) had some experiential training during year 2 as part of the workplace placement and workplace-learning component of their programs. All students at the PAI had experiential training in year 2 while 39 students $(92.9 \%)$ at the HDI were employed in year 2. Most of the students as expected worked for either construction companies $(61.7 \%)$ or quantity surveying practices $(18.3 \%)$. A wider range of types of enterprises employed students from the HDI than from the PAI.

\section{Length of employment}

The length of time that students were employed ranged from 6 months to 5 years. Most students $(52.4 \%)$ were employed for the prescribed 12 months. The mean period of employment was 1.16 years. Students at the PAI worked for a mean period of 1.30 years while their counterparts at the $\mathrm{HDI}$ worked for a mean period of 1.08 years. Only one student at the PAI worked for less than the prescribed 12month period while 14 students at the HDI worked for shorter periods.

\section{Satisfaction with placement}

Both technikons endeavour to place their first year students with prospective employers for their second year. The PAI employed a full-time academic staff member to exclusively attend to industry placement and monitoring of their students. On the other hand, the $\mathrm{HDI}$ allocated industry placement and monitoring of their students to a staff member in addition to other academic responsibilities. Despite this difference in approach students generally had favourable attitudes towards the manner in which their placements had been handled. This finding is confirmed by the mean of the responses to this question being 3.62 on a Likert scale of 1 to 5 , with $1=$ very dissatisfied and $5=$ very satisfied. Most students were either 'satisfied' (37.7\%) or 'very satisfied' (26.2\%). This result is shown in Table 7.

At the PAl the mean response with respect to placement was 4.09 on the 5-point scale. Most students were either 'satisfied' (30.4\%) or 'very satisfied' (47.8\%).

At the $\mathrm{HDI}$ the mean response with respect to placement was 3.34. The largest proportion of students was 'satisfied' $(42.1 \%)$. Large numbers of students were either 'dissatisfied' $(18.4 \%)$ or had 'neutral feelings' $(18.4 \%)$ about their industry placement. Only $13.2 \%$ were 'very satisfied' with their placement.

\section{Satisfaction with monitoring}

Each institution monitors the progress of their second year students during their experiential learning period of employment. The students are generally visited at their place of work. Students were satisfied with the way their experiential learning was monitored. This finding is confirmed by the mean of 3.59 on the 5 -point scale. Most students again were either 'satisfied' $(32.8 \%)$ or 'very satisfied' (24.6\%). A significant number of students $(26.2 \%)$ had 'neutral' attitudes about the monitoring of their experiential training. This result is shown in Table 6. 


\begin{tabular}{|c|c|c|c|c|c|c|}
\hline & $\begin{array}{c}\text { Very dissatisfied } \\
1\end{array}$ & $\begin{array}{c}\text { Not satisfied } \\
2\end{array}$ & $\begin{array}{c}\text { Neither satisfied } \\
\text { nor dissatisfied } \\
3\end{array}$ & $\begin{array}{c}\text { Satisfied } \\
4\end{array}$ & $\begin{array}{c}\text { Very satisfied } \\
5\end{array}$ & Total \\
\hline Placement & $\begin{array}{c}4 \\
6.6 \%\end{array}$ & $\begin{array}{c}9 \\
14.8 \%\end{array}$ & $\begin{array}{c}9 \\
14.8 \%\end{array}$ & $\begin{array}{c}23 \\
37.7 \%\end{array}$ & $\begin{array}{c}16 \\
26.2 \%\end{array}$ & $\begin{array}{c}61 \\
100 \%\end{array}$ \\
\hline Monitoring & $\begin{array}{c}4 \\
6.6 \%\end{array}$ & $\begin{array}{c}6 \\
9.8 \%\end{array}$ & $\begin{array}{c}16 \\
26.2 \%\end{array}$ & $\begin{array}{c}20 \\
32.8 \%\end{array}$ & $\begin{array}{c}15 \\
24.6 \%\end{array}$ & $\begin{array}{c}61 \\
100 \%\end{array}$ \\
\hline Supervision & $\begin{array}{c}4 \\
6.6 \%\end{array}$ & $\begin{array}{c}3 \\
4.8 \%\end{array}$ & $\begin{array}{c}17 \\
27.4 \%\end{array}$ & $\begin{array}{c}19 \\
30.6 \%\end{array}$ & $\begin{array}{c}19 \\
30.6 \%\end{array}$ & $\begin{array}{c}62 \\
100 \%\end{array}$ \\
\hline Experience & $\begin{array}{c}2 \\
3.2 \%\end{array}$ & $\begin{array}{c}8 \\
12.7 \%\end{array}$ & $\begin{array}{c}8 \\
12.7 \%\end{array}$ & $\begin{array}{c}24 \\
38.1 \%\end{array}$ & $\begin{array}{c}21 \\
33.3 \%\end{array}$ & $\begin{array}{c}63 \\
100 \%\end{array}$ \\
\hline
\end{tabular}

Table 7: Satisfaction with aspects of in-service training

At the PAl the mean response with respect to monitoring was 3.63. Most students were either 'satisfied' $(37.5 \%)$ or 'very satisfied' (25.0\%). A significant number of students $(20.8 \%)$ had 'neutral' attitudes about the monitoring of their experiential training.

At the HDI the mean response with respect to monitoring was 3.57. Many students were either 'satisfied' $(29.7 \%)$ or 'very satisfied' (24.3\%). A significant number of students $(29.7 \%)$ had 'neutral' attitudes about the monitoring of their experiential training. Like with placement, a larger proportion of students at the HDI had neutral feelings about the monitoring of their practical year in industry.

\section{Satisfaction with supervision}

Employers supervise second year students during their experiential learning period of employment. Students were satisfied with the way their experiential learning was supervised. This finding is confirmed by the mean of 3.74 . Most students again were either 'satisfied' (30.6\%) or 'very satisfied' (30.6\%). A significant number of students (27.4\%) had 'neutral' attitudes about the monitoring of their experiential training. This result is shown in Table 7.

At the PAl the mean response with respect to supervision was 3.96. Many students again were either 'satisfied' $(25.0 \%)$ or 'very satisfied' $(41.7 \%)$. A significant number of students $(25.0 \%)$ had 'neutral' attitudes about the monitoring of their experiential training. At the $\mathrm{HDI}$ the mean response with respect to supervision was 3.61. Many students again were either 'satisfied' (34.2\%) or 'very satisfied' $(23.7 \%)$. As with other aspects of their experience, a smaller proportion of students at the HDI than at the PAl regarded the supervision of their year 2 as 'very satisfied'. A significant number of students $(28.9 \%)$ had 'neutral' attitudes about the supervision of their experiential training.

\section{Satisfaction with experience gained}

Students were even more satisfied with the experience they had gained during their period of experiential learning. This finding is confirmed by the mean of 3.86. Most students again were either 'satisfied' (30.6\%) or 'very satisfied' (30.6\%). This result is shown in Table 7.
At the PAl the mean response with respect to experience gained was 4.13. Most students again were either 'satisfied' $(25.0 \%)$ or 'very satisfied' (54.2\%). At the HDI the mean response with respect to experience gained was 3.69. Most students were either 'satisfied' (46.2\%) or 'very satisfied' $(20.5 \%)$. As before, a smaller proportion of students at the $\mathrm{HDI}$ than at the PAI regarded the experience gained during their year 2 as 'very satisfied'.

\section{Satisfaction with aspects of year 2 experience}

By analysing the means of the responses of students regarding their experience during year 2 , the various aspects were ranked with respect to the degree of satisfaction they felt. This result is shown in Table 7.

\begin{tabular}{|l|c|c|c|}
\hline & \multicolumn{3}{|c|}{ Rankings by means } \\
\hline Aspect & Sample & PAl & HDI \\
\hline Placement & $3.62(3)$ & $4.09(2)$ & $3.34(4)$ \\
\hline Monitoring & $3.59(4)$ & $3.63(4)$ & $3.57(3)$ \\
\hline Supervision & $3.74(2)$ & $3.96(3)$ & $3.61(2)$ \\
\hline Experience gained & $3.86(1)$ & $4.13(1)$ & $3.69(1)$ \\
\hline
\end{tabular}

Table 8: Satisfaction with aspects of year 2

Students generally expressed the highest level of satisfaction with the experience they gained during year 2 followed by the supervision they received from their respective employers. They were least satisfied with the level of monitoring they received from their respective institutions. Students at the PAI were 'very satisfied' with the experience they gained followed by the way their placement had been handled. They were least satisfied with the monitoring of their practical year. On the other hand, students at the HDI were more satisfied with the aspects that employers were responsible for, namely experience gained and supervision. They were least satisfied with the level of monitoring - more so than their counterparts at the PAI. In all cases the mean scores for student attitudes at the HDI were lower than those of their counterparts, possibly indicative of a greater degree of negativity towards their experience in industry.

Adequacy of year 1 as preparation for year 2

From Table 9 it is evident that most of the students (44.6\%) regarded the adequacy of the year 1 academic courses as 'average' with respect to preparation for the practical year 2 . 
Only $15.4 \%$ of students regarded the year 1 courses as 'very well'. The mean of responses was 3.29 on the 5-point scale.

\begin{tabular}{|c|c|c|c|c|c|}
\hline Very poorly & Poorly & Average & Well & Very well & Total \\
\hline 1 & 12 & 29 & 13 & 10 & 65 \\
$1.5 \%$ & $18.5 \%$ & $44.6 \%$ & $20.0 \%$ & $15.4 \%$ & $100 \%$ \\
\hline
\end{tabular}

Table 9: Adequacy of year 1 as preparation for year 2

At the PAl the mean of responses was 3.96. A large number of students $(20.8 \%)$ viewed the adequacy of the year 1 academic course as 'average', while even more (37.5\%) regarded the course as 'well' and slightly fewer (33.3\%) as 'very well'. At the HDI the mean of responses was 2.90 . Many students (58.5\%) viewed the adequacy of the year 1 academic course as 'average', while fewer (24.4\%) regarded the course as 'poorly'.

Most of the students (34.6\%) who regarded the course as inadequate to prepare them for year 2 indicated 'much of year 1 was irrelevant in the field'. This finding was true for students irrespective of institution.

Most of the students (19.2\%) who felt that the course was adequate 'knew enough to be able to start work'. This finding was again true for students irrespective of the institution they attended. Students at the HDI were more opinioned about this issue than their counterparts at the PAI.

\section{Adequacy of experiential training}

in year 2 in preparation for year 3

From Table 10, it is evident that most students thought the experiential training during year 2 was adequate preparation for year 3. Almost half of the students (47.6\%) students regarded the training as 'well' and $19.0 \%$ regarded the training as 'very well'. The mean of responses was 3.71 on the 5-point scale.

\begin{tabular}{|c|c|c|c|c|c|}
\hline Very poorly & Poorly & Average & Well & Very well & Total \\
\hline 2 & 5 & 14 & 30 & 12 & 63 \\
$3.2 \%$ & $7.9 \%$ & $22.2 \%$ & $47.6 \%$ & $19.0 \%$ & $100 \%$ \\
\hline
\end{tabular}

Table 10: Experiential training in year 2 as preparation for year 3

At the PAl many students (41.7\%) regarded the training as 'well' and $25.0 \%$ regarded the training as 'very well'. A third of the students regarded the training as 'average'. The mean of responses was 4.25 . At the $\mathrm{HDI}$ many students $(51.3 \%)$ regarded the training as 'well' and $15.4 \%$ regarded the training as 'very well'. The mean of responses was 3.59. A smaller proportion of students at the HDI than their counterparts regarded the training as 'very well'.

Most of the students (35.8\%) who regarded the course as adequate to prepare them for year 2 opined, 'the work in year 3 was more familiar'. This was true for students at both institutions with a larger proportion at the HDI. They (20.8\%) also opined that they had 'gained experience and confidence'. In this case a smaller proportion of students at the HDI than at the PAl expressed the same opinion. Most of the students $(17.0 \%)$ who felt that year 2 was inadequate 'did not gain much experience'. A larger proportion of students at the HDI than the PAl felt the same way. Students $(5.7 \%)$ also thought that they did not have as 'much site experience as I would've liked'. As with other issues, students at the HDI were more opinionated about this issue than their counterparts at the PAI.

\section{Relevance of subjects offered to the work situation}

The data in Table 11 indicate that most students felt that the subjects offered in the present course were relevant to the work situation with $40.3 \%$ thinking the subjects were 'relevant' and $29.0 \%$ that the subjects were 'very relevant'. The mean of responses was 3.92 on the 5-point scale.

\begin{tabular}{|c|c|c|c|c|c|}
\hline $\begin{array}{c}\text { Very } \\
\text { irrelevant }\end{array}$ & Irrelevant & Average & Relevant & $\begin{array}{c}\text { Very } \\
\text { relevant }\end{array}$ & Total \\
\hline 2 & & 17 & 25 & 18 & 62 \\
$3.2 \%$ & - & $27.4 \%$ & $40.3 \%$ & $29.0 \%$ & $100 \%$ \\
\hline
\end{tabular}

Table 11: Relevance of the subject offered in the present to the work situation

At the PAl, $41.7 \%$ each thought the subjects were either 'relevant' or 'very relevant'. The mean of responses was 4.25. At the HDI, 39.5\% each thought the subjects were 'relevant' and $21.1 \%$ that they were 'very relevant'. However, more than a third $(34.2 \%)$ of the students at the HDI thought the relevance of subjects to the work situation were 'average'. The mean of responses was 3.71 . This finding suggests that students at the PAI had a more positive attitude about the relevance of the subjects to the work situation.

Most of the students $(27.8 \%)$ who regarded the subjects as relevant indicated that 'everything done at work [was] being taught this year'. They (11.1\%) also opined that the 'work was similar'. Most of the students $(22.2 \%)$ who thought the subjects were irrelevant suggested that the 'work at tech does not always relate to what is done at work'. They $(19.4 \%)$ also indicated that 'only some subjects are relevant'.

As before students at the HDI were more opinionated about this issue than their counterparts at the PAl. Where students from the different institutions expressed their opinions these were in line with those of the whole sample.

\section{Nature of course}

The data in Table 12 indicates that most of the students regarded the course as more academic than practical. The mean of responses about academic nature was 3.57 on the 5-point scale. At the PAI, the mean of responses was 3.74. More than half of the students $(56.5 \%)$ rated the academic nature of the program as 4 . However, a significant proportion of students $(34.8 \%)$ had neutral feelings about this aspect of the program. At the HDI, the mean of responses was 3.47. A much smaller proportion of the 
students $(28.9 \%)$ than at the PAl rated the academic nature of the program as 4 . However, a large number of students $(39.5 \%)$ had neutral feelings about this aspect of their respective programs.

\begin{tabular}{|l|c|c|c|c|c|c|}
\hline Nature & 1 & $\mathbf{2}$ & $\mathbf{3}$ & $\mathbf{4}$ & $\mathbf{5}$ & Total \\
\hline & 2 & 3 & 23 & 24 & 9 & 61 \\
Academic & $3.3 \%$ & $4.9 \%$ & $37.7 \%$ & $39.3 \%$ & $14.8 \%$ & $100 \%$ \\
\hline & 4 & 7 & 25 & 18 & 7 & 61 \\
Practical & $6.6 \%$ & $11.5 \%$ & $41.0 \%$ & $29.5 \%$ & $11.5 \%$ & $100 \%$ \\
\hline
\end{tabular}

Table 12: Nature of program

The mean of responses for the entire sample about the practicality of the course was 3.28 . At the PAl, the mean of responses was 3.46. A large proportion of the students $(45.8 \%)$ rated the practicality of the program 4 . However, many students $(41.7 \%)$ had neutral feelings about this aspect of the program. At the $\mathrm{HDI}$, the mean of responses was 3.16. A much smaller proportion of the students (18.9\%) than at the PAl rated the practicality of the program 4. However, a similar proportion of students $(40.5 \%)$ had neutral feelings about this aspect of the program.

However, when comparing the means of the responses to the aspects of practicality and academic nature of the course, students irrespective of institution regarded the course as more academic than practical.

Students who thought the course was too academic opined as follows:

- Needs improvement/more practicals; and

- Does not get to grips with industry needs.

Those who thought that the course was not too academic responded as follows:

- Need theory before practice;

- Provides some understanding of the industry; and

- Covers most of the theory needed for job.

A larger proportion $(66.7 \%)$ of students at the HDI than the PAI (12.5\%) felt that the program 'needs improvement [and] more practicals'. On the other hand, a larger proportion of the students at the PAI $(25.0 \%)$ than the HDI $(6.7 \%)$ felt that they '[needed] theory before practice'.

A larger proportion of students at the PAI (40.0\%) than at the $\mathrm{HDI}(6.7 \%)$ felt that the program 'needs more effort into practicals'. All the students who felt that the 'work at tech [was] too theoretical [and needed] more site visits' were from the HDI. Similarly, all the students who felt that a 'balanced approach' was followed were from the PAI.

\section{Socio-economic and political relevance} and responsiveness of course

Most students regarded the program as relevant and responsive to the economic, social and political needs of South Africa. The mean of their responses was 3.68 on the 5-point scale. However, a significant number of students $(40.4 \%)$ had neutral feelings about this aspect of the program. This result is shown in Table 13.

\begin{tabular}{|c|c|c|c|c|c|}
\hline $\mathbf{1}$ & $\mathbf{2}$ & $\mathbf{3}$ & $\mathbf{4}$ & $\mathbf{5}$ & Total \\
\hline 1 & - & 23 & 25 & 8 & 57 \\
$1.8 \%$ & - & $40.4 \%$ & $43.9 \%$ & $14.0 \%$ & $100 \%$ \\
\hline
\end{tabular}

Table 13: Relevance and responsiveness of program to economic, social and political needs of South Africa

At the PAl, the mean of the responses of students was 3.78 . However, a large number of students $(39.1 \%)$ had neutral feelings about this aspect of the program. At the $\mathrm{HDI}$, the mean of the responses of students was 3.62. However, many students (33.3\%) had neutral feelings about this aspect of the program. There was not much difference in the responses between students at the two institutions.

Some of the reasons students at the HDI gave for their responses relative to whether the program was relevant and responsive to the socio-economic and political needs of the country included:

- Allows for affirmative action to become reality;

- Important to economy to have best QS's available;

- Equips us to contribute to infrastructure/economic development;

- Average and needs improvement;

- Exposed to what needed internationally;

- Too irrelevant to express an opinion; and

- Upgrade content of courses will improve contribution.

The reason given by students at the PAI was that the program 'equips us to contribute to infrastructure [and] economic development'. Clearly students at the HDI were more opinioned about the socio-civic relevance and responsiveness of the program. This might be indicative of the fact that students and staff at these institutions are historically more sensitised to this aspect of South African society.

\section{DISCUSSION}

There are real concerns in the construction industry about whether construction-related curriculums adequately prepare students for their future careers in the industry. This research project sought from students' perspectives to determine whether they perceived a disjunction between theory and practice. The study also sought to determine if there were differences between the opinions and attitudes of students attending an $\mathrm{HDI}$ and those attending a PAI. As Ross and Elechi (2002) pointed out in their study, it might be questionable to expect students to validly determine the disjunction between theory and practice. However, students are one of the three cooperative partners in the cooperative education model. This particular study sought, therefore, to examine the attitudes of construction students concerning their own learning experience relative to their career 
preparation. The results of the surveys of students' attitudes regarding their cooperative education experiences confirm in the main the findings in the literature on this educational approach.

Generally, first year students had favourable attitudes towards the course content of the year preceding their practical year. This attitude was influenced by their perception that the subjects offered in the classroom situation were directly based on and related to the construction industry. Almost all students, irrespective of the institution they were at, thought that these subjects were relevant and responsive to the needs of the industry. While senior students also agreed with this finding a large number of them at the HDI had neutral feelings about the relevance of the program to the work situation. These students contended that work at the education institution did not 'relate to what is done at work'. However, in addressing this perceived shortcoming, caution needs to be exercised that the cooperative curriculum does not become too narrow resulting in an unbalanced approach that elevates workplace training to suit only the demands of the construction industry. This caution is necessary against employers' permanent complaints about the poor outputs from schooling and higher education. Rather, students should be equipped to tackle workplace and wider socio-civic issues and problems (Wraga, 1998; White Paper, 1997; Graham and McKenzie, 1995).

Further, the majority of students irrespective of institution expressed satisfaction with the subjects that made up the first year course. However, there was also a sizable dissatisfaction factor with many students at each institution either being outright dissatisfied with first year subjects or not being sure. A larger proportion of students at the HDI were dissatisfied. There is probably a need for a simple conceptual model that integrates course objectives with work-based outcomes, preferably around a specific project or set of competencies (Schaafsma, 1996). Students, faculty members, and employers could, and should, work together to create practical educational problems that narrow the gap between the needs and expectations of the academic and industry (Smith, 2000).

Most students thought that the first year course prepared them sufficiently for their practical stint in industry. Students recognised the link between theory and practice and opined, 'Theory prepares for practical'. A larger proportion of students at the PAI than their HDI counterparts had favourable attitudes. Those who disagreed-mostly from the $\mathrm{HDI}$-suggested that they needed to 'work with real materials' during their workshop and/or laboratory sessions. The large proportion of students at both institutions who expressed that they did not 'know what to expect from inservice training,' suggests a need for briefing sessions before industry placement. Schaafsma (1996) in his study supports this finding by recommending that a set of guidelines for briefing and debriefing sessions is necessary to prepare students to provide evidence of measurable learning outcomes from sources such as log books and project reports. Contrary to the opinions of first year students, senior students who had been working in industry regarded the adequacy of the first year course as average with respect to whether it prepared them sufficiently for their practical year in industry. This response was prompted by 'much of year one being irrelevant in the field' and workplace. Further, a large number of students at both institutions had neutral attitudes about this aspect of their program. A possible explanation might be that first year students provided their opinions based on their expectations before they had gone into industry. The senior students provided more reflective responses informed by their experience-albeit limited.

Irrespective of institution, most first year students thought the course was not too academic. Those who thought it was, suggested that practical aspects and site visits needed more emphasis. Senior students disagreed with this sentiment in that most of them regarded the course as more academic than practical. They agreed that 'more practicals' had to be included in the academic component. Smith (2000:243) supports this finding when she suggests that

'learner-centered methods of teaching help students understand work-related problems and also develop a range of solutions that can be tested before trying to use them at work'.

Most of the senior (third and fourth year) students had the prescribed 12-month period of experiential training. However, a larger proportion of students at the HDI worked for shorter periods than 12 months. These students also worked at a much wider range of types of construction enterprises. While students at the PAI worked for construction firms, subcontractors, and QS firms, those at the HDI worked for contractors, municipalities, consultants, suppliers, community organisations, developers and subcontractors. This finding suggests that the either the industry placement strategy employed by the PAI was either more successful or construction industry employers preferred to employ students from the PAI. With respect to the former, the PAI employed a full-time staff member charged with the sole responsibility of placing and monitoring students during their second year. It is also possible that the PAI was consequently able to seek and secure placements earlier that in the case of the HDI.

The findings suggest that employers were fulfiling their role as one of the partners in the cooperative education model by providing valuable industry experience and supervision in the workplace. On the other hand, the academic institutions need to revisit their monitoring and placement roles to ensure a greater degree of: 
- Satisfaction by students with their cooperative experience; and

- Employability and resilience of students to workplace and workforce changes (Smith, 2000).

A large proportion of students at the $\mathrm{HDI}$ expressed either dissatisfaction or neutral attitudes about their industry placement suggesting that the industry placement strategy employed by the PAl was more successful with respect to achieving a greater level of student satisfaction. Similarly, a large proportion of students at the HDI had neutral feelings about their year two monitoring suggesting that the PAI approach to monitoring of their second year students in industry might be more satisfactory. With respect to all aspects of their practical year, the mean scores of the HDI students were lower than their PAI counterparts. This finding hints at underlying problems with the practical year two that deserves further investigation. Possible reasons could be:

- The lack of resources for the HDI to employ a full-time person to solely attend to industry placement and monitoring;

- Use of an ineffective approach to placement and monitoring;

- Prejudice against employing students from the HDI by employers; and

- Preference by employers to use students from the HDI as a form of cheap manual labour.

Of concern is the large number of students at each institution who had neutral attitudes about the relevance and responsiveness of the program to the economic, social and political needs of the country. This finding suggests that both higher education institutions had possibly failed to prepare students to address emerging societal problems and contribute to the social, cultural and economic development of South African society.

\section{CONCLUSION}

This study sought to validate from student perceptions whether higher education institutions fulfiled their objectives relative to construction-related programs, namely, the preparation of persons to address emerging societal problems; whether their cooperative education experience fostered and promoted the connection between academic preparation and job requirements; whether the present programs enhanced appreciation of the concepts learned in the classroom after their application in the field; and whether the students' direct hands-on experience prepared them for their future careers.

The findings of the study suggest that much more needs to be done to ensure that students are adequately prepared outside of the confines of a traditionally narrow curriculum to address the socio-civic needs of society. Similarly, while the cooperative experience of students suggested that employers fulfiled their role by supervising them and ensuring that they gained adequate practical and meaningful experience, higher education institutions needed to do more to close the gap between academic preparation and job requirements. This is particularly true for HDls. Specific projects that integrate course objectives with work-based outcomes could be effective in addressing this issue. Additionally, guidelines for briefing and debriefing sessions are necessary to better prepare students for their cooperative experience. More effective placements and monitoring during their period in employment might contribute to improved employability and resilience of students to workplace and workforce changes. Returning students confirmed that their practical period in industry enhanced their understanding of concepts in the classroom during their third and final years of study. However, it was inconclusive whether their direct hands-on experience prepared them for their future careers in construction. While junior and senior students had different opinions about the disjunction between classroom learning and workplace experience, it is evident that all cooperative partners, namely academic institution, student and employer, need to work together to improve the cooperative construction education experience.

The differences in the opinions and attitudes between students at the PAI and the HDI suggest that institutional redress as envisaged in government policy had not necessarily occurred. Prima facie, the inherited inequalities between HDIs and PAls while not necessarily intensifying had not diminished.

The author is presently concluding a study into the attitudes of employers about cooperative construction education with a view to improving the experience of construction management students at higher education institutions.

\section{REFERENCES}

Cook, J.S. and Cook, L.L. (1998). How technology enables the quality of student-centered learning, Quality Progress, July, 59-63.

Ellington, H., Gordon, M., and Fowlie, J. (1998). Using Games and Simulations in the Classroom, London, Kogan Page.

Fellows, R. and Liu, A. (1997). Research Methods for Construction, Oxford, Blackwell Science.

Frain, P. (1992). Multiplicity in Action: co-operation between higher education and industry in Ireland, European Journal of Education, 27(4), 349-364.

Gordon, G., Hage, H., and McBride, R. (2001). Criminal Justice Internship: Theory into Practice, Cincinnati, Anderson Publishing. 
Graham, C. and McKenzie, A. (1995). Delivering the promise: the transition from higher education to work, Education + Training, 37(1), 4-11.

Guillard, H. and Garnier, P. (2001). Editorial, Basin News, 2, December, 2.

Hicks, R.E. (1996). Experiential Learning in a Postgraduate Project Management Program, Education + Training, 38(3), 28-38.

Kim, B., Williams, R. and Dattilo, J. (2002). Students' Perception of Interactive Learning Modules, Journal of Research and Technology in Education, 34(4), 453-473.

Rainsbury, E., Hodges, D., Sutherland, J., and Barrow, M. (1998). Academic, Employer and Student Collaborative Assessment in a Work-based Cooperative Education Course, Assessment and Evaluation in Higher Education, 23(3), 313-324.

Ross, L.E. and Elechi, O.O. (2002). Student Attitudes towards Internship Experiences: From Theory to Practice, Journal of Criminal Justice Education, 13(2), 297-312.

Sanyal, C.C. (1991). Higher education and the labour market, In P.G. Altbach (ed.), Higher Education:

An Encyclopaedia, 1, 147-168.

Schaafsma, H. (1996). Back to the real world: work placements revisited, Education + Training, 38 (1), 5-13.

Smith, E.A. (2000). Applying knowledge-enabling methods in the classroom and in the workplace, Journal of Workplace Learning, 12(6), 236-244.

White Paper (1997). Education White Paper 3:

A Programme for the Transformation of Higher Education, Pretoria, Department of Education.

Wraga, W.G. (1998). The School-to-work movement in the United States: policies, problems and possibilities,

The Curriculum Journal, 9(2), 177-195. 